University of Nebraska - Lincoln

DigitalCommons@University of Nebraska - Lincoln

Faculty Publications, Department of Psychology

Psychology, Department of

January 2003

\title{
Altered reward value of carbohydrate snacks for female smokers withdrawn from nicotine
}

\author{
Bonnie Spring \\ University of Illinois - Chicago \\ Sherry Pagoto \\ University of Illinois - Chicago \\ Dennis E. McChargue \\ University of Nebraska-Lincoln, dmcchargue2@unl.edu \\ Donald Hedeker \\ University of Illinois - Chicago \\ Jessica Werth \\ University of Illinois - Chicago
}

Follow this and additional works at: https://digitalcommons.unl.edu/psychfacpub

Part of the Psychiatry and Psychology Commons

Spring, Bonnie; Pagoto, Sherry; McChargue, Dennis E.; Hedeker, Donald; and Werth, Jessica, "Altered reward value of carbohydrate snacks for female smokers withdrawn from nicotine" (2003). Faculty Publications, Department of Psychology. 305.

https://digitalcommons.unl.edu/psychfacpub/305

This Article is brought to you for free and open access by the Psychology, Department of at DigitalCommons@University of Nebraska - Lincoln. It has been accepted for inclusion in Faculty Publications, Department of Psychology by an authorized administrator of DigitalCommons@University of Nebraska - Lincoln. 


\title{
Altered reward value of carbohydrate snacks for female smokers withdrawn from nicotine
}

\author{
Bonnie Spring $^{\mathrm{a}, \mathrm{b}, *}$, Sherry Pagoto ${ }^{\mathrm{a}, \mathrm{b}}$, Dennis McChargue ${ }^{\mathrm{a}, \mathrm{b}}$, Donald Hedeker ${ }^{\mathrm{c}}$, Jessica Werth ${ }^{\mathrm{a}, \mathrm{b}}$ \\ "Department of Psychology, University of Illinois Chicago, Chicago, IL, USA \\ ${ }^{b}$ Department of Psychology, Edward Hines, Ir: VA Hospital, Hines, IL, USA \\ 'Division of Epidemiology, and Biostatistics, University of Illinois Chicago, Chicago, IL, USA
}

Received 11 March 2003; received in revised form 14 August 2003; accepted 22 August 2003

\begin{abstract}
Discontinuing nicotine intake usually results in weight gain partially due to heightened energy intake from between-meal snacks. This experiment tested the hypothesis that the reinforcing value of palatable carbohydrate-rich snacks increases for female smokers during nicotine deprivation. Eighteen smokers and 18 nonsmokers completed a concurrent-schedules operant computer task on two separate days. Smokers were bioverified abstinent at the second testing. The operant task allowed participants to earn points redecmable for either carbohydrate snacks or money on concurrent variable-ratio schedules of reinforcement. There were five different probabilities of earning points redeemable for snacks $(8 \%, 16 \%, 25 \%, 50 \%, 75 \%)$, while the probability of earning points redeemable for money remained fixed at $25 \%$. Reward value of snacks was measured by switch point: the reinforcement ratio at which the effort required to earn snacks exceeded their value to the respondent, as signified by a shift to working for money. Results showed that smokers undergoing nicotine deprivation persisted in working for snacks into leaner reinforcement schedules than nonsmokers $(P=026)$. Furthermore, nicotine deprivation increased smokers' allocation of effort to earn snack foods relative to their own behavior when smoking ( $P=.006$ ). Variation in palatability or hunger did not cxplain these differences in snack reward value. Findings indicate that nicotine deprivation is associated with a heightened reward value of appealing snack foods for female smokers.
\end{abstract}

Keywords: Reinforcing value; Nicotine withdrawal; Carbohydrate snacks; Female smokers; Cigarette smoking

\section{Introduction}

Nicotine is demonstrably the tobacco constituent that reinforces cigarette smoking, a major cause of morbidity and mortality (U.S. Department of Health and Human Services [USDHHS], 1998, 2001). Discontinuing nicotine intake usually results in weight gain, which is normative after quitting smoking and greater among females than males (Klesges et al., 1989, 1997; Williamson et al., 1991). Withdrawing nicotine alters energy balance and causes weight gain partly via loss of nicotine's enhancement of energy expenditure (Perkins et al., 1992), but more prominently via increased energy intake (Klesges et al., 1989; Perkins, 1993; Vander Weg et al., 2001). Heightened

* Corresponding author. Department of Psychology (M/C 285), University of Illinois Chicago, $1007 \mathrm{~W}$. Harrison Street, Chicago, IL 60067, USA. Tel.: +1-312-413-2628; fax: +1-312-355-2155.

E-mail address: bspring@uic.edu (B. Spring). calorie intake of approximately $100 \cdot 300 \mathrm{kcal} /$ day usually begins immediately after smoking cessation (Klesges et al., 1989) and derives in large part from between-meal snacks (Gilbert and Pope, 1985).

The causes of increased snacking triggered by nicotine deprivation remain unclear, but two classes of explanation warrant consideration. The first is that smokers undergoing nicotine deprivation eat more because they are hungrier. Increased hunger due to loss of nicotine's pharmacological suppressant effect on appetite could stimulate initiation of meals or could heighten between-meal snacking by reducing the satiating power of meals (Epstein et al., 1991; Perkins et al., 1991, 1995). A second class of explanation is that nicotine deprivation produces a reward deficiency state that heightens the incentive appeal of accessible rewards, increasing their motivational salience. The latter explanation, consistent with incentive-sensitization theory (Robinson and Berridge, 2001), was tested in the current study. 
In incentive-sensitization theory, Robinson and Berridge (2001) posit a distinction between "liking" and "wanting" for self-administered substances like drugs or food. They propose that the two behavioral processes are independent of each other and are subserved by different neurobiological mechanisms. Liking for a food can be indexed by its rated palatability. Wanting, on the other hand, is indexed by the compound's reward or reinforcing value, measurable by how hard the organism is willing to work to attain it. Contrary to the common wisdom that we self-administer substances compulsively because we like them, Robinson and Berridge postulate that we do so because we want them, regardless of whether we like them or even find them revolting, as can occur during self-administration binging. Considerable animal and human research demonstrates that self-administration of palatable foods increases after nicotine deprivation (Carroll et al., 1991; Hughes et al., 1991; Ogden, 1994; Spring et al., 1991). Consistent with incentive-sensitization theory, the current study tested the hypotheses that nicotine deprivation would increase wanting for snacks, indexed by their reward value, without augmenting hunger or increasing liking for snacks, indexed by their rated palatability.

Some ambiguity exists about what properties characterize snack foods whose intake increases preferentially during nicotine deprivation. Researchers who examine postcessation choice between snack foods containing either chiefly carbohydrate or chiefly protein usually detect selective postcessation increases in the intake of sweets, carbohydrates, and sometimes fat, but rarely protein (Spring et al., 1991). Conversely, increased intake of all macronutrients is usually seen when participants are only given a choice among foods that mix protein and carbohydrate (Perkins et al., 1991; Vander Weg et al., 2001). Although sweets intake is usually increased, most research fails to demonstrate an increase in the self-reported palatability of sweets after smoking cessation (Perkins et al., 1990; Redington, 1984; Rodin, 1987). To accommodate these ambiguities, the current research examined changes in the reward value of snacks that were high in carbohydrate, low in protein, highly palatable, and either sweet or nonsweet according to participant preferences. Females were studied because they gain more weight than males after quitting smoking (Williamson et al., 1991) and express greater concern about postcessation weight gain (Pirie et al., 1991).

In what is, to our knowledge, the only prior human study of nicotine's effect on the reward value of foods, Perkins et al. (1995) observed increases in food's reward value only among nicotine-deprived female smokers who were high in dietary restraint: chronically concerned about dieting to attempt to maintain an unreasonably low body weight. The eating context examined by Perkins et al. (1995) differed importantly from the usual snacking context though. Mixed nutrient foods (e.g., turkey sandwich) were presented after participants fasted overnight through the following noontime and had just consumed a condensed milk preload. Topographically, then, reward value was assessed for foods that served as part of a first meal of the day, i.e., noontime brunch, reversing a period of energy deprivation. Thus, although the protocol was consistent with the aim of quantifying nicotine's effect on the satiating power of meals, it may not have captured nicotine effects on snacking between meals during the usual late afternoon or early evening hours when most snacks are eaten (Cross et al., 1994; Wurtman et al., 1987). The distinction is important to the extent that nicotine deprivation increases eating that serves a function different than redressing generalized energy deficits. Elsewhere, it has been suggested that snack self-administration serves a mood regulatory function, possibly via effects on brain serotonin, for clinical syndromes like nicotine withdrawal that are characterized by dysphoric mood, carbohydrate snacking, and weight gain (Bowen et al., 1991; Fernstrom and Wurtman, 1971; Grunberg, 1986; Spring et al., 1987).

\section{Materials and methods}

\subsection{Study design and entry criteria}

Two groups of participants (smokers and nonsmokers) underwent individual laboratory behavioral testing on two occasions separated by a 2-day interval. Smokers were still smoking at the initial behavioral test session and were bioverified as abstinent at the second. Order was not counterbalanced because 2 days of nicotine deprivation were presumed to produce sustained effects on brain chemistry that rendered the biological effects of resuming smoking different from those of continuous smoking. The study was approved by the local Institutional Review Board. Participants were recruited by fliers and screened initially via a structured telephone interview (inquiring about age; self-reported use of tobacco, alcohol, and other drugs; snacking behavior, medical history). On Study Day 1, participants came to the laboratory to undergo the consent process, finish being screened, and be trained on the behavioral task. On Study Day 2, they underwent baseline behavioral testing. Smokers quit smoking on the evening of Study Day 2 and, on day 3, came to the laboratory for abstinence bioverification. On Study Day 4, both nonsmokers and smokers underwent the second behavioral test session (after again bioverifying abstinence for the smokers). Study Days 2, 3, and 4 were consecutive.

All enrollees needed to meet the following inclusion criteria: (1) female between the ages of 18-50 years; (2) afternoon snacker who meets structured interview criteria for consuming snacks with at least a 3:1 ratio of carbohydrate to protein three or more afternoons per week. Smokers were required to smoke 20 or more cigarettes per day or score 6 or more on the Fagerstrom Tolerance Questionnaire (FTQ) (Fagerstrom, 1978), have been smoking for at least 1 year and not currently intending to quit. Other entry criteria 
excluded candidates who (1) were diabetic, hypoglycemic, or had any other disease that restricted consumption of specific foods; (2) customarily ingested caffeinated beverages at times other than in the morning; (3) were pregnant or lactating; (4) were currently taking psychiatric medications, or medications known to affect appetite; (5) were actively abusing drugs or alcohol; (6) had a history of eating disorder; or (7) were currently depressed [indexed by a Beck Depression Inventory (BDI) (Beck et al., 1961) score $>15$ ], because of appetite changes that can accompany depression. Smokers were required to remain abstinent during Study Days 3 and 4 as evidenced by ecolyzerverified carbon monoxide levels $<8 \mathrm{ppm}$. (Attained values were $M=4.8($ S.D. $=1.9)$ on Day 3 and $M=3.2$ (S.D. $=1.8)$ on Day 4).

\subsubsection{Participants}

Participants were 36 females: 18 smokers and 18 nonsmokers. Smokers had a mean age of 32.9 (S.D. $=9.6)$ years and mean education of 13.8 years $($ S.D. $=2.7)$. They were nondepressed (BDI: $M=5.6$, S.D. $=4.9$ ), moderate - heavy smokers, having smoked an average of 21.8 cigarettes per day (S.D. $=9.1$ ) for 16.5 (S.D. $=9.6)$ years. They scored $M=6.6$ (S.D. $=1.3$ ) on the FTQ, indicating that they were at least moderately dependent on nicotine. Nonsmokers had a mean age of 26.7 (S.D. $=7.9$ ) years, averaged 15.6 $($ S.D. $=2.0)$ years of education, and were nondepressed (mean BDI score $=3.9$, S.D. $=3.8$ ). Smokers were significantly older than nonsmokers $(t=2.15, d f=34, P=.04)$, but had fewer years of education $(t=2.25, d f=34, P=.03)$. No significant between group differences were found on BDI scores, body mass index (BMI; Garrow and Webster, 1985) or weekly snack frequency. Both smokers and nonsmokers were somewhat dissatisfied with their weights (smoker: $M=2.0$, S.D. $=9$; nonsmoker: $M=2.5$, S.D. $=1.4$ ) and reported that weight was moderately important to their selfesteem (smoker: $M=3.7$, S.D. $=1.1$; nonsmoker: $M=3.5$, S.D. $=1.2$, respectively). Both groups snacked most frequently in the afternoon. Seventy-eight percent of the sample was Caucasian, 19\% was African American, and 3\% was Asian.

\subsection{Measures}

\subsubsection{Fagerstrom Tolerance Questionnaire}

The FTQ (Fagerstrom, 1978) is an 8-item questionnaire that measures nicotine dependence. A score $\geq 7$ is indicative of physical dependence on nicotine (Fagerstrom and Schneider, 1998). So that all participants who smoked were at least moderately dependent on nicotine, they were required to smoke at least 20 cigarettes a day or score $\geq 6$ on the FTQ.

\subsubsection{Beck Depression Inventory}

Composed of 21 items that assess cognitive, affective, and psychomotor symptoms of depression, the BDI is $83 \%$ accurate in discriminating patients with current major de- pression from nonpatient controls (Beck et al., 1961). The scale has high internal consistency and construct validity in discriminating depressed from nondepressed individuals (Richter et al., 1998).

\subsubsection{Body mass index}

BMI was calculated using the formula: (weight in pounds/(height in inches) $\left.)^{2}\right) \times 704.5$ (Garrow and Webster, 1985).

\subsubsection{Weight concern}

Two items assessed participants' satisfaction with their current weight and the importance of weight to their selfesteem. Participants reported their responses on 5-point scales $(1=$ very dissatisfied, very unimportant, $5=$ very satisfied, very important).

\subsubsection{Food preference rating scale}

Participants selected snack options from a list of 15 commercially available snack foods that were high in nonfructose sources of carbohydrate and low in protein $(>6: 1$ ratio of carbohydrate:protein), with variable fat content. Both sweet and savory snack choices were available (e.g., chocolate candy, jellybeans, granola, chocolate chip cookies, shortbread cookies, potato chips, popcorn, Cheetos), as were several beverages (e.g., cola, lemon lime soda, root beer, fruit punch). After tasting, participants rank-ordered their top three snack choices and top beverage choice. The three highest ranked snack foods and the top-ranked beverage were the snack selections that participants worked to earn in test sessions.

\subsubsection{Hunger and palatability rating scale}

At the beginning of both baseline and $48 \mathrm{~h}$ sessions, participants rated their hunger on a 10-point scale where $1=$ not at all hungry and $10=$ very hungry. After consuming the snacks they earned during the Apple Picker task, participants rated their liking for their chosen snack foods and beverage on 10-point scales where $1=$ liked not at all and $10=$ liked very much.

\subsubsection{Concurrent-schedules operant computer task}

Reinforcing value was quantified via the Apple Picker (Norman and Jongerius, 1985; Lappalainen and Epstein, 1990; Perkins et al., 1995) a concurrent-schedules operant computer task that enabled participants to work for points ("Apples") redeemable for either snack foods or money. In the Apple Picker, two variable ratio schedules of reinforcement operated concurrently. The procedure consisted of two screens ("orchards") each associated with its own reinforcement schedule. Each screen presented a grid of 100 "X"s or "O"s ("trees"), some proportion of which hid "apples." Participants used a computer mouse to select ("pick") trees. If a tree contained an apple, the letter " $A$ " flashed briefly on the screen, sounding a tone and augmenting the apple tally for that orchard, which was displayed at 
the bottom of the screen. The escape button on the keyboard enabled the participant to toggle back and forth between orchards.

During training, participants learned that apples found in the $\mathrm{X}$ orchard were redeemable for money, whereas apples found in the $O$ orchard were redeemable for snack foods. Reinforcement schedule was manipulated by varying the probability of finding apples in each of the two orchards. In the X (money) orchard, the percentage of trees with apples was always $25 \%$, which corresponded to a variable-ratio reinforcement schedule of VR4. In the $O$ (snack food) orchard, the proportion of trees planted with apples was variable. Participants experienced five different probabilities of finding apples in the snack food orchard: $8 \%$ (VR12.5), 16\% (VR6.25), 25\% (VR4), 50\% (VR2), and $75 \%$ (VR1.33). Each ratio was presented once in an ascending series and once in a descending series, with the starting order counterbalanced across participants. Thus, in each session participants engaged in a total of 10 trials: either $8 \%, 16 \%, 25 \%, 50 \%, 75 \%-10$-min break-75\%, $50 \%, 25 \%, 16 \%, 8 \%$; or $75 \%, 50 \%, 25 \%, 16 \%, 8 \%-10$ min break-8\%,16\%,25\%,50\%,75\%. Participants began each reinforcement ratio with 50 picks that they allocated across the two orchards. Thus, they allocated 100 picks per ratio (50 ascending, 50 descending) at five ratios, or 500 total picks per Apple Picker session. The number of picks expended in the snack orchard indexed the effort the participant chose to devote to earning snacks versus money.

To encourage responding based on felt motivation rather than intellectual analysis, participants were instructed to allocate picks according to what they felt like working towards and how easy or hard it was to find apples in the orchards. Before each ascending and descending schedule, participants completed a practice trial in which they devoted 10 picks to each orchard, enabling them to experience the probabilities of earning apples in the snack and money orchards. They were told that the ease of earning snacks relative to money varied, but no instruction was provided regarding computation of probabilities or the sequence of schedules. Participants were told that the Apple Picker task lasted $45 \mathrm{~min}$, at the end of which the points (apples) earned would be exchanged for snack foods and/or money. Ten apples from the money orchard were exchangeable for 10 cents. Ten apples from the food orchard were redeemable for a 75-kcal portion of one of the participant's three most preferred snack foods or a $75-\mathrm{kcal}$ portion of the most preferred beverage.

The reinforcement ratio of 10 cents: $75 \mathrm{kcal}$ of food was chosen based on pilot testing that compared reinforcement ratios of 10 cents: $150 \mathrm{kcal}$ food versus 10 cents: $75 \mathrm{kcal}$ food. At both ratios, pilot participants earned an average eight food rewards per session and worked somewhat harder to earn money than food, consistent with previous findings for nondeprived participants (Epstein et al., 1991; Lappalainen and Epstein, 1990). The 10 cent:150 kcal ratio resulted in earning 1200 total kilocalories of food, an amount larger than the typical afternoon snack. In contrast, the 10 cent: $75 \mathrm{kcal}$ ratio resulted in earning $600 \mathrm{kcal}$, a reasonable snack intake, and was therefore used in the present study. Participants were reminded that they would remain in the laboratory for $2 \mathrm{~h}$ after the Apple Picker task, during which they could eat the snacks they had earned and water, but nothing else. Confinement to the laboratory made the value of snacks salient because task responding offered the only proximal source of food.

The reward value of snacks relative to money for a given participant was inferred from the switch point: the reinforcement schedule at which the effort required to earn snacks exceeded their value for an individual, who then shifted her effort towards earning money. The operational definition of switch point was the reinforcement schedule at which a participant no longer allocated a majority $(>50 \%)$ of her picks for snacks, and shifted to allocating a majority of her picks for money. In the current protocol, the probability of earning snacks was greater than the probability of earning money at the $75 \%$ and $50 \%$ schedules, equivalent at the $25 \%$ schedule, and lower at the $16 \%$ and $8 \%$ schedules. Thus, a participant whose pick allocations matched the objective probability would allocate $>50 \%$ picks to food at the $75 \%$ and $50 \%$ schedules and show a switch point to money responding at the $16 \%$ schedule, dedicating $>50 \%$ picks to money at both the $16 \%$ and $8 \%$ schedules. On the other hand, someone who found money very highly rewarding might allocate a majority of picks to snacks at the $75 \%$ schedule, but switch to majority money responding at the $50 \%$ schedule, even though the probability of earning snacks remained relatively more favorable. If she allocated $>50 \%$ picks to money consistently across the $50 \%, 25 \%$, $16 \%$, and $8 \%$ schedules, her switch point would be coded $50 \%$. Conversely, the participant who found snacks especially highly rewarding might allocate $>50 \%$ picks to snacks at the $75 \%, 50 \%, 25 \%$, and even the $16 \%$ schedules, showing a switch point to majority money responding only at the $8 \%$ schedule. Or she might never shift: allocating $>50 \%$ picks to snacks even at the $8 \%$ schedule, in which case her switch point would be coded as zero.

\subsection{Procedures}

After initial telephone screening, study candidates attended a total of four visits to complete screening and protocol. All participants completed the study during selfreported Days 7-21 of their menstrual cycles to avoid possible perimenstrual changes in appetite or food preferences. Day 1 involved informed consent, completion of screening and preliminary measures (BDI, BMI, FTQ, assessment of snack intake, and Food Preference Rating Scales) and training on the Apple Picker computer game. Day 2 involved collection of baseline behavioral choice data. Participants who smoked discontinued nicotine use at 8 p.m. on Day 2 and remained abstinent through completion 
of study procedures on Day 4 . They visited the laboratory on Day 3 to have abstinence bioverified via ecolyzer (CO $<8 \mathrm{ppm}$ ). On Day 4 , all participants returned to the laboratory to complete the second session of behavioral choice testing. Smokers were again bioverified abstinent before undergoing testing. After the protocol concluded on Day 4, participants were paid for their participation and debriefed regarding the purpose of the study.

Participants ate as usual throughout Study Days 1 and 3 and after leaving the laboratory on behavioral testing Days 2 and 4. For test days, participants were given prepackaged foods (i.e., a granola bar, $8 \mathrm{oz}$ of skim milk, and $8 \mathrm{oz}$ of orange juice) to eat as breakfast at home. They were asked to drink their usual amount of morning caffeine (to avoid caffeine withdrawal) and not to eat any additional foods until lunch. At noon in the laboratory they ate a $300-\mathrm{cal}$ lunch (turkey and cheese sandwich on wheat bread, mustard or nonfat mayonnaise, noncaffeinated diet soda) and then nothing except water until after behavioral testing. On Day 2 , smokers were permitted to smoke as usual. They were asked to smoke a cigarette at 2:30 p.m. before beginning Apple Picker testing at 2:45 p.m. in order to standardize pretask nicotine exposure and minimize withdrawal effects on behavioral choice.

One portion of each participant's three most preferred snack foods, a portion of her preferred beverage, and a dime were placed within view during Apple Picker testing. At the end of the test session, apples accumulated across all trials were exchanged for earned snack and money rewards. So that the earned snacks would be the only accessible source of food, participants were required to remain in the laboratory for $2 \mathrm{~h}$ after testing ended, during which time they were able to eat only the snacks that they had earned during the session. Smokers were permitted to smoke as desired on Day 2 but were required to remain abstinent on Day 4.

\subsection{Statistical procedures}

Switch point, total snack picks, and total calories derived from the Apple Picker task were the primary dependent variables. Preliminary inspection of the data distributions indicated that all variables were approximately normally distributed; no outliers were detected. Next, preliminary $t$ tests were undertaken to test whether switch points differed between the ascending and descending series. Then, data were subjected to $2 \times 2$ mixed model analyses of variance (ANOVA) with group (smoker vs. nonsmoker) as the between-subjects factor, time (baseline vs. $48 \mathrm{~h}$ ) as the within-subjects factor, and a random subjects effect to account for the repeated observations. A Group $\times$ Time interaction was predicted for switch point such that after 2 days of nicotine deprivation, smokers were expected to persist at working chiefly for snacks into leaner reinforcement schedules than nonsmokers and nondeprived smokers. Leaner reinforcement schedules are those $(16 \%, 8 \%)$ at which fewer snack than money picks are reinforced, or 0 , which signifies failure to ever shift to money responding. Group $\times$ Time interactions were also predicted for total snack picks and calories such that from baseline to $48 \mathrm{~h}$, snack picks and calories would increase for smokers (nicotine deprivation) but not for nonsmokers. Rated snack palatability and hunger were secondary outcomes and were analyzed via ANOVA. Hunger ratings were analyzed via $2 \times 2$ mixed model ANOVA with group (smoker, nonsmoker) as the between subjects factor, time (Day 2, Day 4) as the within-subjects factor, and a random subjects effect to account for the repeated observations. Finally, palatability was analyzed via 2 (group) $\times 2$ (time) $\times 4$ (snack option: 3 highly rated solid foods, 1 highly rated beverage) ANOVA with group as the between-subjects factor and time and snack as within-subjects factors. No changes or between group differences in hunger or snack palatability were expected.

\section{Results}

\subsection{Preliminary analyses}

No significant differences were revealed by $t$ tests between switch points for the ascending versus descending series for smokers or nonsmokers on Day 2 or 4 . Consequently, each participant's switch point in the ascending series was averaged with the switch point in the descending series to represent the mean switch point.

Analysis of snack palatability revealed no main effects or interactions involving group, time, or snack. Nonsmokers' mean snack/beverage palatability ratings were 8.67 (1.74) at Time 1 and $8.61(2.38)$ at Time 2. Smokers' mean palatability ratings were $9.39(1.18)$ at time 1 and $8.52(2.35)$ at Time 2 . Findings suggest that snack palatability was adequately matched across groups and remained stable over time. The ANOVA on hunger ratings revealed a significant main effect of group, $F(1,33)=8.35, P=.007$, and no main effects or interactions involving time. Averaging across both testing sessions, smokers $(M=3.81$; S.D. $=2.58)$ rated themselves as hungrier than nonsmokers $(M=2.09$; S.D. $=1.24)$.

\subsection{Responding for snacks}

A 2 (group) $\times 2$ (time) ANOVA revealed a significant Group $\times$ Time interaction for switch point $F(1,32)=6.31$, $P=.017$. A supplementary $t$ test comparing the two groups at baseline detected no differences between the switch points of smokers $(M=41.5)$ and nonsmokers $(M=37.27)$, $t(33)=1.71, P=.20$. (Means represent average schedules across participants, not actual schedules.) After $48 \mathrm{~h}$ in nicotine withdrawal, however, the a priori comparison indicated that smokers had significantly lower switch points $(M=26.6)$ than did nonsmokers $(M=47.17), t(33)=3.70$, $P=013$. Simple effects were analyzed by within-subjects repeated measures ANOVAs comparing each group's switch 
points at baseline and Time 2 . Those analyses indicated that there were no significant changes across time for nonsmokers, $F(1,17)=1.885, P=.188$, but a marginally significant lowering of switch point after $48 \mathrm{~h}$ of nicotine deprivation for smokers $F(1,17)=3.65, P=.07$. As Fig. 1 indicates, for both smokers and nonsmokers at baseline, the average point of switching to majority money responding fell numerically in between the $50 \%$ and the $25 \%$ schedules, indicating that participants shifted to working for money even when the probability of earning snacks remained more favorable ( $50 \%$ schedule) or equivalent ( $25 \%$ schedule). Fig. 2 shows results for the second test session, which occurred after 48 -h abstinence for smokers. Whereas the average nonsmoker continued to switch to money responding at a point mathematically between the $50 \%$ and $25 \%$ schedules, the switch point for the average abstinent smoker shifted to the $16 \%$ schedule. Thus, once abstinent, the average smoker persisted in working for snacks into "thinner" reward schedules at which she could earn money as easily or more easily.

Analysis of total snack responses revealed, as predicted, a significant Group $\times$ Time interaction $F(4,32)=6.78$, $P=.01$ (Fig. 3). Simple effects were interpreted via repeated measures ANOVAs within each group, testing the hypotheses that smokers undergoing withdrawal would increase their responding for snacks, whereas nonsmokers' snack choices would remain unchanged. As hypothesized, smokers worked significantly harder (i.e., spent more picks) to earn snack foods after 48-h nicotine deprivation $(M=270.5$, S.D. $=101.65)$ than when smoking at baseline $(M=230.16$, S.D. $=81.66), F(1,17)=10.16, P=.005$. In contrast, there was no significant change $(P=36)$ in the number of picks

\section{Switchpoint from Majority Snack Responding: Baseline}

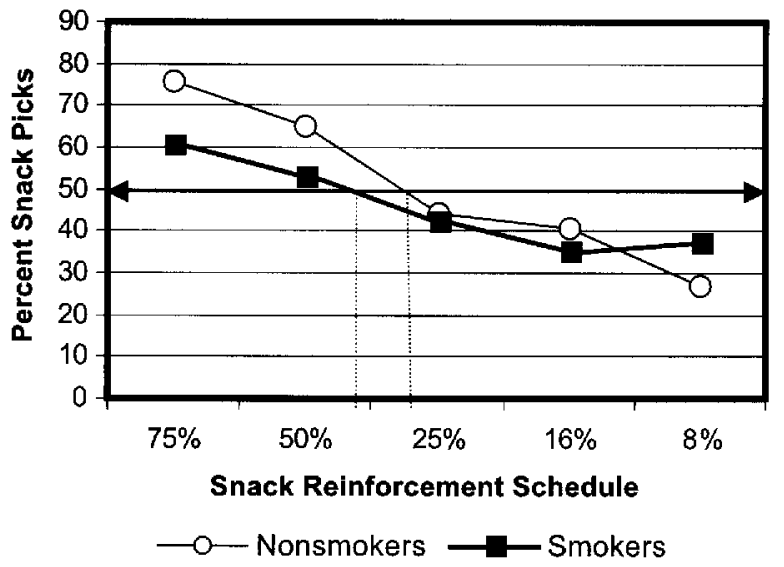

Fig. 1. Percent of picks allocated to snacks on the Apple Picker task at baseline by smokers smoking and by nonsmokers as a function of reinforcement schedule, where probability of earning snacks varies as $8 \%$, $16 \%, 25 \%, 50 \%$, and $75 \%$, and probability of earning money remains $25 \%$. The solid horizontal line originating at 50 on the $Y$ axis indicates the point at which $50 \%$ of picks are allocated to snacks and $50 \%$ to money. Switch point, shown by the dotted vertical line, estimates the reinforcement schedule at which the group shifts from majority snack to majority money responding.

\section{Switchpoint from Majority Snack Responding: 48 Hours}

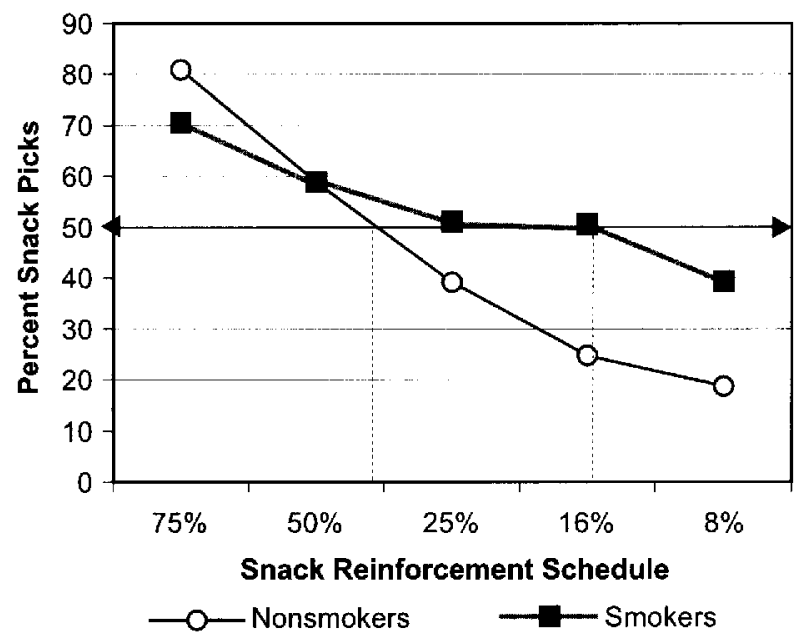

Fig. 2. Switch point at retesting $48 \mathrm{~h}$ after baseline for nonsmokers and smokers withdrawn from nicotine for days.

nonsmokers allocated to the snack orchard at the second test session $(M=224.22$, S.D. $=111.61)$ compared to baseline $(M=253.55$, S.D. $=84.68)$.

\subsection{Total calories earned}

Total calories earned on the Apple Picker task was calculated by multiplying the number of snack rewards earned by $75 \mathrm{kcal}$. A $2 \times 2$ ANOVA on earned calories revealed a significant Group $\times$ Time interaction $F(4,32)=$ 4.32, $P=.046$ (Fig. 4). Repeated measures ANOVAs conducted within each group tested the hypothesis that earned calories increased for smokers more than for nonsmokers from baseline to $48 \mathrm{~h}$. Results revealed that smokers earned significantly more snack calories during nicotine deprivation $(M=797.95$, S.D. $=314.08)$ compared to baseline

Snack Picks: Group x Time

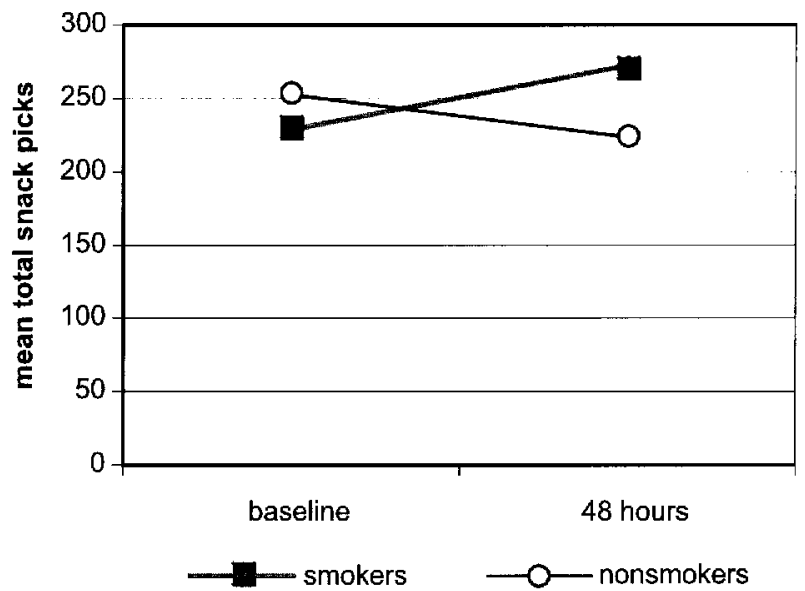

Fig. 3. Mean total number of picks (out of 500 possible) allocated for snacks versus money by smokers while smoking and after 48 -h nicotine deprivation and by nonsmokers tested and retested at the same interval. 
Earned Snack calories: Group x Time

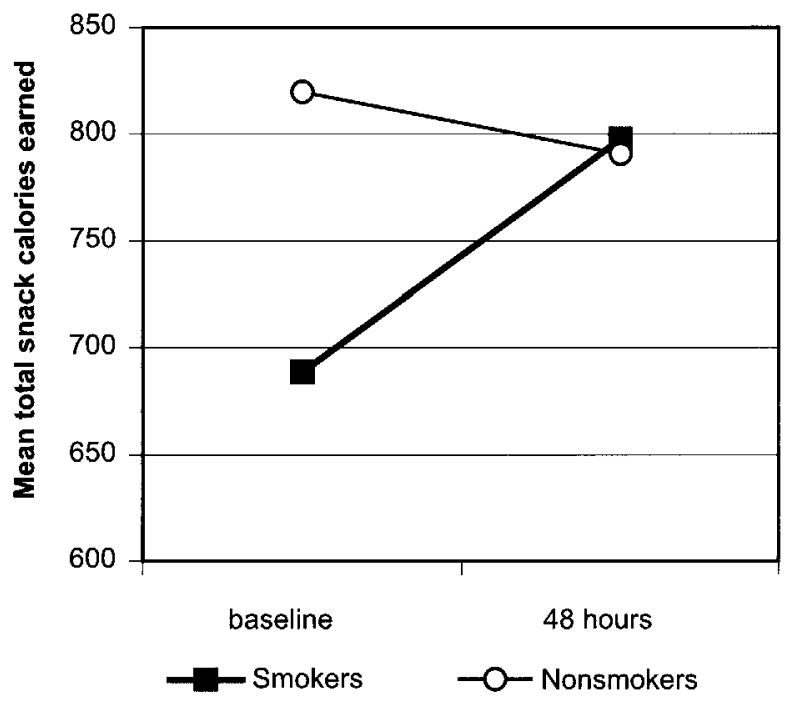

Fig. 4. Mean snack calories earned by smokers while smoking and after 48- $\mathrm{h}$ nicotine deprivation and by nonsmokers tested and retested at the same interval.

$(M=688.88$, S.D. $=245.30), F(1,17)=6.11, P=.02$. In contrast, for nonsmokers there were no significant differences in snacks earned at $48 \mathrm{~h}(M=791.06$, S.D. $=245.32)$ compared to baseline $(M=820.02$, S.D. $=221.15) F(1,17)=.253$, $P=62$. Thus, nicotine deprivation motivated the average smoker to allocate sufficient resources to earn 109 additional snack kilocalories on the Apple Picker task. Bear in mind that although the average smoker made 40.5 more snack picks after nicotine withdrawal than while smoking, picks were only intermittently reinforced by finding apples that could be traded in for snacks. If the task reinforcement probabilities had not varied and if every pick allocated to the snack orchard had yielded an apple, then the nicotinedeprived smoker would have earned four more snacks than at baseline, adding $300 \mathrm{kcal}$ from snacks.

\section{Discussion}

The results indicate that female smokers undergoing nicotine withdrawal increase their effort to obtain snacks relative to money, allocate more resources to acquiring snacks, and earn more snack calories than their nonsmoking counterparts. Findings accord with the premise that nicotine deprivation increases the reward value of appealing carbohydrate snacks for female smokers. The increased reward value of snacks during nicotine withdrawal parallels and may help to explain the heightened intake of energy generally and carbohydrate treats particularly that has been documented among smokers undergoing nicotine withdrawal (Klesges et al., 1989; Spring et al., 1991; Hall et al., 1989) and that contributes to postcessation weight gain (Hall et al., 1989; Stamford et al., 1986). Lack of evidence that carbo- hydrates or sweets become more palatable after smoking discontinuation (Perkins et al., 1990; Redington, 1984; Rodin, 1987) has made it difficult to explain why snacking increases after nicotine withdrawal. However, the present study demonstrates that an increase in hunger or palatability is not a necessary precondition for a rise in either the reward value or the consumption of preferred carbohydrate snacks after nicotine withdrawal.

Since the increased reward value of preferred carbohydrate snacks after nicotine deprivation was not attributable to changes in palatability or hunger, alternative causal models of increased snacking are needed. One possible explanation is that because nicotine suppresses hunger, smokers experience both heightened food cravings and heightened cigarette cravings after nicotine is withdrawn and confuse the two sensations. Evidence that administration of either glucose or nicotine satisfies either craving is consistent with that interpretation (Ogden, 1994; West, 2001).

Alternative explanations attribute the heightened reward value of snacking to dysregulations in brain serotonergic and dopaminergic neurotransmission that are triggered by nicotine administration and withdrawal. Acute nicotine administration increases prefrontal cortical serotonin release and extracellular concentration (Toth et al., 1992; Ribeiro et al., 1993; Summers and Giacobini, 1995), and chronic administration increases release from dorsal raphe (Mihailescu et al., 2002). Discontinuing nicotine diminishes serotonin turnover (Koob and Le Moal, 2001; Watkins et al., 2000 ) and triggers a withdrawal state that is characterized by dysphoric mood and carbohydrate craving (Spring et al., 1987). Increased carbohydrate snacking, which elevates brain tryptophan influx and serotonin synthesis (Fernstrom and Wurtman, 1971) may represent a form of substance selfadministration that is reinforced by positive mood changes (Spring et al., 1987). Consistent with that interpretation are findings indicating that dysphoric mood and carbohydrate snacking during nicotine withdrawal are reduced by agents that enhance serotonergic neurotransmission (Bowen et al., 1991; Covey et al., 2002; Killen et al., 2001; Spring et al., 1991).

Via action on nicotinic acetylcholine receptors in the mesolimbic dopamine system, acute nicotine administration releases dopamine (Lindstrom, 1997). Robinson and Berridge (2001) posit that repeated drug administration sensitizes the dopamine system, yielding heightened wanting for the drug, indexed by its increased incentive salience and elevated reward value. According to Robinson and Berridge (2001), it is this dopaminergically mediated process of reward "wanting" that underlies compulsive reward selfadministration and heightened intake. Conversely, they posit that "liking" for a reward (indexed by its rated palatability) is an orthogonal process, mediated via different neurochemical pathways, and unrelated to appetitive behavior or intake (Wyvell and Berridge, 2002). Incentive sensitization theory is unique in offering an explanation of the observed paradox 
that nicotine withdrawal heightens the reward value of preferred snacks and, as shown elsewhere (e.g., Spring et al., 1991), their consumption, even though their perceived palatability remains unchanged.

Changes in serotonergic and dopaminergic activity triggered by nicotine withdrawal may act synergistically to heighten the reward value of palatable snacks. Enhanced serotonergic activity has been shown to facilitate dopamine release in the nucleus accumbens (Benloucif and Galloway, 1991; De Deuwaerdere et al., 1996), and to increase sensitivity to reward (Sasaki-Adams and Kelley, 2001). Conversely, decreased release of serotonin inhibits dopaminergic activity (Ichikawa et al., 1995) and is thought to diminish sensitivity to reward (Zagen et al., 2001). Viewed thusly, self-administration of palatable, high carbohydrate snacks could serve the dual functions of increasing serotonin release and thus secondarily enhancing dopamine release and pleasure.

Whereas Perkins et al. (1995) observed only increased reward value of food after nicotine deprivation among a subset of weight-concerned female smokers, we found the effect more broadly among female smokers. Those differing results are probably attributable to differences in our experimental protocols. Unlike Perkins et al. (1995), we examined the reward value of between-meal snacks rather than meals, and assessed participants in the midafternoon, when snacking is prevalent. Furthermore, our participants had no access to foods other than those they earned for $2 \mathrm{~h}$ after the concurrent schedules task. Also differing from Perkins et al. (1995), all of our snacks were high in carbohydrate and low in protein.

The present study had several limitations. First, although we controlled for practice effects by retesting nonsmokers after the same interval as smokers, we did not counterbalance the order in which smokers smoked or underwent nicotine withdrawal. We adopted that design because the biobehavioral effects of resuming smoking may differ from those of continued smoking, as has been shown previously (e.g., Bell et al., 1999). We designed our protocol to ascertain whether there is an increase in the reward value of preferred snacks for the chronic smoker who discontinues nicotine self-administration and enters nicotine withdrawal. In contrast, comparing food's reward value during nicotine abstinence to that during subsequently reinitiated smoking would have addressed a different question: whether relapse to smoking decreases the reward value of preferred snack food. Having modeled the progression to abstinence, we can conclude that nicotine withdrawal heightens the reward value of preferred snacks, but we cannot generalize to infer that nicotine reinstatement would diminish snack reward value.

Because we studied females only, it cannot be assumed that nicotine deprivation also increases the reward value of carbohydrate snacks for male smokers. Nor can comparable effects be assumed to generalize to light smokers or to those who do not snack. Additionally, because we did not sys- tematically vary snack properties, it remains unclear whether nicotine withdrawal affects the reward value of snacks differently as a function of their macronutrient content, taste, and palatability. All the snacks we studied were highly palatable, high carbohydrate, low protein, and either sweet or savory.

It is important to consider whether the heightened reward value of preferred snacks is clinically meaningful, perhaps helping to explain weight gain after quitting smoking. Because our observation period was restricted to the first $48 \mathrm{~h}$ after nicotine withdrawal, our findings do not indicate whether the increased reward value of carbohydrate snacks is transitory or longer lasting. However, a long-lasting effect appears likely based on the observations that (a) overeating of carbohydrates persists for at least 1 month after quitting smoking (Spring et al., 1991; Hall et al., 1989); (b) the initial increase in calorie intake predicts weight gain 6 months after quitting (Hall et al., 1989); and (c) weight gain continues for at least 6 months postcessation (Hall et al., 1986) if not for several years (Williamson et al., 1991).

The average nicotine-deprived smoker in the current study significantly increased her carbohydrate snack earnings by $109 \mathrm{kcal}$, whereas nonsmokers' calorie earnings did not change significantly. Otherwise stated, an average female who consumes $1800-2000 \mathrm{kcal} /$ day was motivated by nicotine deprivation to earn an additional $5-6 \%$ calories per day from carbohydrate snacks. It should be noted that the observed 109 -kcal increase reflects only heightened snack acquisition during the several-hour midafternoon period spanned by the Apple Picker protocol. The assessment window does not reflect increased snack intake that may have occurred at other times of day, including evening, when snacking commonly takes place. It is also noteworthy that because we varied the reinforcement schedules on the Apple Picker task, the effort expended to earn snacks did not yield them as reliably as it would in real life, when any trip to the cupboard or grocery store can succeed in yielding a snack. Thus, on the Apple Picker task, the abstinent smoker's increased allocation of 40.5 more picks for snacks only translated into increased snack intake of $109 \mathrm{kcal}$. However, had snacks been as readily accessible as they are in real life, the added resources expended to earn food during this several hour period would have translated into increased snack intake of $300 \mathrm{kcal}$. Increased energy intake of 100-300 kcal/day (Klesges et al., 1989) models the overeating that has been documented in ex-smokers and that accounts for approximately $69 \%$ of the variance in postcessation weight gain (Stamford et al., 1986).

The present results correspond with others suggesting that food and nicotine appear to be substitutable rewards, and that deprivation of one increases the reinforcing value of the other (Carroll et al., 1991; Niaura et al., 1992). The findings also raise an important question regarding the mechanism(s) whereby deprivation of one pleasurable self-administered compound (nicotine) increases the incentive value and selfadministration of another (preferred snacks). The increased 
reward value of snacking for smokers withdrawn from nicotine could arise from several factors. First, it may be important that all of the snacks we studied were high in carbohydrate and low in protein, and thus capable of elevating brain tryptophan influx and serotonin synthesis (Fernstrom and Wurtman, 1971). The shared macronutrient composition of the snacks may have heightened their incentive value for deprived smokers by enabling snack selfadministration to dispel dysphoric moods associated with nicotine withdrawal (Bowen et al., 1991; Spring et al., 1991). Alternatively, the high palatability and preference value of the snack foods may have been their shared critical feature. Perhaps the prospect of self-administering any highly preferred food took on added incentive value during nicotine deprivation because such snacking delivered sufficient pleasure to overcome the elevated reward threshold produced by prolonged nicotine exposure (Epping-Jordan et al., 1998). Finally, the hand-to-mouth topographic similarity between the acts of eating and smoking may have enabled snacking to behaviorally substitute for smoking (Bickel and Vuchinich, 2000). The opportunity to behaviorally substitute self-administration of appealing snacks for self-administration of cigarettes may alleviate feelings of deprivation that could otherwise foster a relapse-tempting rise in the reward value of smoking (Hall et al., 1992).

\section{Acknowledgements}

Supported in part by grants HL52577, HL59348, HL63307, and a VA Merit Review grant to Dr. Spring, and K08 DA00467 to Dr. McChargue.

\section{References}

Beck AT, Ward CH, Mendelson M, Mock J, Erbaugh J. An inventory for measuring depression. Arch Gen Psychiatry 1961;4:561-71.

Bell SL, Taylor RC, Singleton EG, Henningfield JE, Heishman SJ. Smoking after nicotine deprivation enhances cognitive performance and decreases tobacco craving in drug abusers. Nicotine Tob Res 1999;1:45-52.

Benloucif S, Galloway MP. Facilitation of dopamine release in vivo be serotonin agonists: studies with microdialysis. Eur J Pharmacol 1991; 200:1-8.

Bickel WK, Vuchinich RE. Reframing health behavior change with behavioral economics. Mahwah (NJ): Erlbaum; 2000.

Bowen DJ, Spring B, Fox E. Tryptophan and high carbohydrate diets as adjuncts to smoking cessation therapy. J Behav Med 1991;41: $97-110$

Carroll ME, Carmona GG, May SA. Modifying drug-reinforced behavior by altering the economic conditions of the drug and a nondrug reinforcer. J Exp Anal Behav 1991;56:361-76.

Covey LS, Glassman AH, Stetner F, Rivelli S, Stage K. A randomized trial of sertraline as a cessation aid for smokers with a history of major depression. Am J Psychiatry 2002;159(10):1731-7.

Cross AT, Babicz D, Cushman LF. Snacking pattems among 1,800 adults and children. J Am Diet Assoc 1994;94(12):1398-403.

De Deurwaerdere P, Bonhomme N, Lucas G, Le Moal M, Spampinato U. Serotonin enhances striatal dopamine outflow in vivo through dopamine uptakes sites. Neurochemistry 1996;66:210-5.
Epping-Jordan MP, Watkins SS, Koob GF, Markou A. Dramatic decreases in brain reward function during nicotine withdrawal. Nature 1998; 393:76-9.

Epstein LH, Bulik CM, Perkins KA, Caggiula AR, Rodefer J. Behavioral economic analysis of smoking: money and food as alternatives. Pharmacol Biochem Behav 1991;38:715-21.

Fagerstrom KO. Measuring degree of physical dependence to tobacco smoking with reference to individualization of treatment. Addict Behav $1978 ; 3: 235-41$.

Fagerstrom KO, Schneider NG. Measuring nicotine dependence: a review of the Fagerstrom Tolerance Questionnaire. J Behav Med 1998;12: $159-82$.

Fernstrom JD, Wurtman RJ. Brain serotonin content: increase following ingestion of carbohydrate diet. Science 1971;174:1023-5.

Garrow JS, Webster J. Quetelet's index (W/H2) as a measure of fatness. Int J Obes 1985;9:147-53.

Gilbert RM, Pope MA. Early effects of quitting smoking. Psychopharmacology 1985;78:121-7.

Grunberg NE. Behavioral and biological factors in the relationship between tobacco use and body weight. In: Katkin ES, Manuck SB, editors. Advances in behavioral medicine, vol. 2. Greenwich (CT): JAI Press; 1986. p. $97-129$.

Hall SM, Ginsberg D, Jones RT. Smoking cessation and weight gain. J Consult Clin Psychol 1986;54:342-6.

Hall SM, McGee R, Tunstall C, Duffy J, Benowitz N. Changes in food intake and activity after quitting smoking. J Consult Clin Psychol $1989 ; 57: 81-6$.

Hall SM, Tunstall CD, Vila KL, Duffy J. Weight gain prevention and smoking cessation: cautionary findings. Am J Public Health 1992; 82(6):799-803

Hughes JR, Gust SW, Skoog K, Keenan RM, Fenwick JW. Symptoms of tobacco withdrawal: a replication and extension. Arch Gen Psychiatry 1991;48:52-9.

Ichikawa J, Kuroki T, Kitchen MT, Meltzer HY. R(+)-8-OH-DPAT, a 5HT1A receptor agonist, inhibits amphetamine-induced dopamine release in rat striatum and nucleus accumbens. Eur J Pharmacol 1995; 287:179-84

Killen JD, Ammerman S, Rojas N, Varady J, Haydel F, Robinson TN. Do adolescent smokers experience withdrawal effects when deprived of nicotine? Exp Clin Psychopharmacol 2001;9(2):176-82.

Klesges RC, Meyers AW, Klesges LM, LaVasque M. Smoking, body weight, and their effects on smoking behavior: a comprehensive review of the literature. Psychol Bull 1989;106:204-30.

Klesges RC, Winders SE, Meyers AW, Eck LH, et al. How much weight gain occurs following smoking cessation: a comparison of weight gain using both continuous and point prevalence abstinence. $\mathbf{J}$ Consult Clin Psychol 1997;65(2):286-91.

Koob GF, Le Moal M. Drug addiction, dysregulation of reward, and allostasis. Neuropsychopharmacology 2001;24(2):97-129.

Lappalainen R, Epstein LH. A behavioral economics analysis of food choice in humans. Appetite 1990;14(2):81-93.

Lindstrom J. Nicotinic acetylcholine receptors in health and disease. Mol Neurobiol 1997;15(2):193-222.

Mihailescu S, Guzman-Marin R, Dominguez Mdel C, Drucker-Colin R. Mechanisms of nicotine actions on dorsal raphe serotoninergic neurons. Eur J Pharmacol 2002;452(1):77-82.

Niaura R, Clark MM, Raciti MA, Pera V, Abrams DB. Increased saliva cotinine concentrations in smokers during rapid weight loss. J Consult Clin Psychol 1992;60:985-7.

Norman W, Jongerius JL. Apple Picker: computer software for studying human responding on concurrent and multiple schedules. Behav Res Methods Instrum Comput 1985;17(2):222-5.

Ogden $\mathbf{J}$. Effects of smoking cessation, restrained eating, and motivational states on food intake in the laboratory. Health Psychol 1994;13(2): $114-21$.

Perkins KA. Weight gain following smoking cessation. J Consult Clin Psychol 1993;61:678-777. 
Perkins KA, Epstein LH, Pastor S. Changes in energy balance following smoking cessation and resumption of smoking in women. $J$ Consult Clin Psychol 1990;58:121-5.

Perkins KA, Epstein LH, Stiller RL, Fernstrom MH, Sexton JE, Jacob RG, et al. Acute effects of nicotine on hunger and caloric intake in smokers and nonsmokers. Psychopharmacology 1991;103:103-9.

Perkins KA, Epstein LH, Sexton JE, Solberg-Kassel R, Stiller RL, Jacob RG. Effects of nicotine on hunger and eating in male and female smokers. Psychopharmacology 1992;106(1):53-9.

Perkins KA, Epstein LH, Fonte C, Mitchell SL, Grobe JE. Gender, dietary restraint, and smoking's influence on hunger and the reinforcing value of food. Physiol Behav 1995;57:675-80.

Pirie PL, Murray DM, Luepker RV. Gender differences in cigarette smoking and quitting in a cohort of young adults. Am J Public Health 1991;81: $324-7$.

Redington $\mathrm{K}$. Taste differences between cigarette smokers and nonsmokers. Pharmacol Biochem Behav 1984;21:203-8.

Ribeiro EB, Bettiker RL, Bogdanov M, Wurtman RJ. Effects of systemic nicotine on serotonin release in rat brain. Brain Res 1993;621(2): 311-8.

Richter P, Werner J, Heerlein A, Kraus A, Heinrich S. On the validity of the Beck Depression Inventory: a review. Psychopathology 1998;31:160-8.

Robinson TE, Berridge KC. Incentive-sensitization and addiction. Addiction 2001;96:103-14.

Rodin $\mathbf{J}$. Weight change following smoking cessation: the role of food intake and exercise. Addict Behav 1987;12:303-17.

Sasaki-Adams DM, Kelley AE. Serotonin-dopamine interactions in the control of conditioned reinforcement and motor behavior. Neuropsychopharmacology 2001;25:440-52.

Spring B, Chiodo J, Bowen D. Carbohydrates, tryptophan and behavior: a methodological review. Psychol Bull 1987;102:234-56.

Spring B, Wurtman J, Gleason R, Wurtman R, Kessler K. Weight gain and food intake after smoking cessation: a preventive intervention using $d$ fenfluramine. Health Psychol 1991;10(3):216-23.

Stamford BA, Matter S, Fell RD, Papanek P. Effects of smoking cessation on weight gain, metabolic rate, caloric consumption, and blood lipids. Am J Clin Nutr 1986;43:486-94.

Summers KL, Giacobini E. Effects of local and repeated systemic admin- istration of $(-)$ nicotine on extracellular levels of acetylcholine, norepinephrine, dopamine, and serotonin in rat cortex. Neurochem Res 1995;20(6):753-9.

Toth E, Sershen H, Hashim A, Vizi ES, Lajtha A. Effect of nicotine on extracellular levels of neurotransmitters assessed by microdialysis in various brain regions: role of glutamic acid. Neurochem Res 1992; $17(3): 265-71$.

U.S. Department of Health and Human Services. The health consequences of smoking: nicotine addiction. Washington (DC): Government Printing Office; 1998.

U.S. Department of Health and Human Services. Women and smoking: a report of the Surgeon General-2001. Washington (DC): U.S. Department of Health and Human Services, Public Health Service, Office of the Assistant Secretary for Health, Office on Smoking and Health, Government Printing Office; 2001.

Vander Weg MW, Klesges RC, Eck Clemens LH, Meyers AW, Pascale RW. Relationships between ethnicity, gender, and short-term changes in energy balance following smoking cessation. Int J Behav Med 2001;8(2): $163-77$.

Watkins SS, Koob GF, Markou A. Neural mechanisms underlying nicotine addiction: acute positive reinforcement and withdrawal. Nicotine Tob Res 2000;2(1):19-37.

West R. Glucose for smoking cessation: does it have a role? CNS Drugs $2001 ; 15: 261-5$.

Williamson DF, Madans J, Anda RF, Kleinman JC, Giovino GA, Byers T. Smoking cessation and severity of weight gain in a national cohort. $\mathrm{N}$ Engl J Med 1991;11:739-45.

Wurtman J, Wurtman R, Reynolds S, Tsay R, Chew B. Fenfluramine suppresses snack intake among carbohydrate cravers but not among noncarbohydrate cravers. Int J Eat Disord 1987;6(6):687-99.

Wyvell CL, Berridge KC. Intra-accumbens amphetamine increases the conditioned incentive salience of sucrose reward: enhancement of reward "wanting" without enhanced "liking" or response reinforcement. J Neurosci 2002;20:8122-30.

Zagen A, Nakash R, Overstreet DH, Yadid G. Association between depressive behavior and absence of serotonin-dopamine interaction in the nucleus accumbens. Psychopharmacology 2001;155:434-9. 